\title{
Caracterização do uso e cobertura do solo do município de Concórdia do Pará utilizando geotecnologias
}

O objetivo deste estudo foi caracterizar espacialmente as áreas alteradas, bem como processos de ocupação do município de Concórdia do Pará, tendo em vista a importância do mapeamento do uso e cobertura do solo. Foram aplicadas técnicas de processamento digital em imagem disponibilizadas da galeria de imagens do Instituto Nacional de Pesquisas (INPE) obtida pela série do satélite Landsat-5/TM de órbita-ponto 223/61. O trabalho contou com metodologia empregada de classificação não supervisionada, os quais foram possíveis obter informações importantes para avaliação do uso e cobertura no município. Verificou-se que o uso e ocupação do solo é constituído por três classificações, respectivamente, floresta madura 7,3\%, vegetação secundária $85,8 \%$ e áreas antropizadas com 6,9\%, também foi verificado concordância das classificações entre o conjunto de dados por meio do índice de Kappa a qual chegou a $41,5 \%$ o que demonstra níve razoável de concordância. A caracterização do uso e cobertura do solo a partir de imagens espaciais é um instrumento que pode fundamentar o planejamento e gestão ambiental.

Palavras-chave: Caracterização espacial; Classificação não supervisionada; SIG

\section{Characterization of the use and coverage of the soil of the municipality of Concódia de Pará using geotechnologies}

The objective of this study was to characterize spatially the altered areas, as well as occupation processes of the municipality of Concórdia do Pará, considering the importance of land use and land cover mapping. Digital image processing techniques available from the National Institute of Images (INPE) image gallery obtained by the Landsat-5/TM satellite series of orbit-dot 223/61 were applied. The work had an unsupervised classification methodology, which allowed to obtain importan information to evaluate the use and coverage in the municipality. It was verified that the use and occupation of the soil is constituted by three classifications, respectively, mature forest $7.3 \%$, secondary vegetation $85.8 \%$ and anthropic areas with $6.9 \%$; it was also verified agreement of the classifications between the data set by means of the Kappa index, which reached $41.5 \%$, which shows a reasonable level of agreement. The characterization of the use and coverage of the soil from spatial images is an instrument which can support environmental planning and management.

Keywords: Spatial characterization; Classification not supervised; SIG

Topic: Ciências Florestais

Reviewed anonymously in the process of blind peer
Received: 04/03/2020

Approved: 25/06/2020
Jéssica Costa dos Santos (iD

Universidade Federal Rural da Amazônia, Brasil http://lattes.cnpq.br/8061391874732225 http://orcid.org/0000-0002-4424-1821

jessicasantos.ufra@gmail.com

Juliana Wanessa Costa Barros (iD

Universidade Federal Rural da Amazônia, Brasil http://lattes.cnpq.br/3641245937304377 http://orcid.org/0000-0002-2955-6104

julianabarros.engflorestal@gmail.com

Flavia Giseli Galvão Marinho

Universidade Federal Rural da Amazônia, Brasil http://lattes.cnpq.br/4983413363361657 gisellimarinho@hotmail.com

\author{
Fernanda Yukari de Souza Sakuma (iD \\ Universidade Federal Rural da Amazônia, Brasil \\ http://lattes.cnpq.br/4305525882492304 \\ http://orcid.org/0000-0003-4107-544X \\ fernandasakuma18@gmail.com \\ Thais de Nazaré Oliveira Novais \\ Universidade Federal Rural da Amazônia, Brasil \\ http://lattes.cnpq.br/0755520013937924 \\ http://orcid.org/0000-0003-3890-3881 \\ thaisnovais4@gmail.com \\ Jorge Lucas Pantoja do Nascimento (it) \\ Universidade Federal Rural da Amazônia, Brasil \\ http://lattes.cnpq.br/6745434856409232 \\ http://orcid.org/0000-0003-2145-0847 \\ jorgelucaspantoja@gmail.com
}

Francimary da Silva Carneiro

Universidade Federal Rural da Amazônia, Brasil http://lattes.cnpq.br/8657235544233319 http://orcid.org/0000-0002-1693-8779

francimarycarneiro@gmail.com
Referencing this:

SANTOS, J. C.; BARROS, J. W. C.; MARINHO, F. G. G.; SAKUMA, F. Y. S.; NOVAIS, T. N. O.; NASCIMENTO, J. L. P.; CANEIRO, F. S.. Caracterização do uso e cobertura do solo do município de Concórdia do Pará utilizando geotecnologias. Natural Resources, v.10, n.2, p.33-37, 2020 DOI: http://doi.org/10.6008/CBPC2237-9290.2020.002.0004 


\section{INTRODUÇÃO}

A caracterização do uso e cobertura da terra através de imagens de satélites fornece informações importantes para identificação e visualização de representações de elementos geométricos, através da interpretação obtida pelo sensoriamento remoto que caracteriza categorias de vegetação natural que reveste o solo, como também suas respectivas localizações (LEITE et al., 2012).

A partir da distribuição espacial das espécies florestais, o potencial produtivo da madeira em seus pontos pode ser verificado, assim, como o crescimento da biomassa e a intervenções ocorridas durante períodos. A aplicação de métodos de interpolação tende a resultar em mapas espaciais com informações precisas, principalmente quando lidar com o volume comercial de espécies arbóreas, tornando-se uma ferramenta muito importante para o manejo florestal (PINHEIRO et al., 2019).

A utilização de produtos do sensoriamento remoto com softwares de SIG (sistemas de informações geográficas) proporciona a obtenção de dados de forma rápida, confiável e repetitiva. Lopes (2008) afirma que o mapeamento do uso e cobertura do solo é fundamental para a deteç̧ão de áreas exploradas de forma inapropriadas e, com sua localização precisa, subsidia as tomadas de decisões pelos órgãos competentes encarregados da fiscalização. Pinheiro et al. (2019) afirma que novas ferramentas para o manejo florestal que ajudam na o reconhecimento e monitoramento dos povoamentos florestais gera informações confiáveis e importantes para o manejo florestal, contribuindo para a sustentabilidade do ecossistema, aumentar o rendimento dos recursos disponíveis, além de reduzindo o desperdício de madeira e os custos operacionais exploração.

É importante que com base nas imagens geradas no monitoramento se faça revisões bibliográficas da área além da validação do local analisado. Segundo Araujo Filho et al. (2007) é fundamental uma boa interpretação buscando as associações de refletâncias, texturas, estruturas e padrões de formas para derivar informações acerca das atividades de uso, a partir do que é basicamente informações de cobertura da terra.

A avaliação do uso e cobertura do solo é de suma importância, tendo em vista identificação dos fenômenos naturais ou antrópicos, que podem estar ocorrendo na área monitorada, por degradação como erosões, assoreamentos ou outras alterações causadas pelo uso não planejado do solo, com base nisto este trabalho teve como objetivo caracterizar espacialmente o uso e ocupação do solo do município de Concórdia do Pará, bem como conhecer a distribuição espacial e quantificação das classes de diferentes usos o solo utilizando técnicas de geoprocessamento e sensoriamento remoto.

\section{MATERIAIS E MÉTODOS}

Concórdia é um município do estado do Pará, pertencente à Microrregião de Tomé-Açu e Mesorregião do Nordeste Paraense, de localização geográfica de latitude: $1^{\circ} 59^{\prime} 30^{\prime \prime}$ Sul, longitude: $47^{\circ} 56^{\prime}$ 58" Oeste. É um município de fácil acesso e diretamente ligada a economia da região metropolitana de Belém, distante $150 \mathrm{~km}$.

A principal atividade econômica no município é a agricultura de subsistência de culturas como 
pimenta do reino, farinha de mandioca e atualmente plantio de dendê por iniciativa de empresas privadas visando produção de biodiesel. Segundo o IBGE (2018), estima-se que município possui 40,84 habitantes $/ \mathrm{km}^{2}$.

A identificação do uso e cobertura do solo no município de Concórdia do Pará, teve início a partir da interpretação de imagens obtidas pela série de satélites Landsat-5/TM de órbita-ponto 223/61, datada em 03 jul. 2008, disponibilizadas pelo Instituto Nacional de Pesquisas Espaciais (INPE). As imagens foram disponibilizadas em arquivo compactado, mas logo em seguida foram descompactadas para serem importadas para o banco de dados do software ArcGIS 10.1. Para análise à identificação do uso e cobertura da terra, foram aplicadas às imagens técnicas de processamento digital, o qual consiste em associar os pixels da imagem às classes individuais que representam objetos reais tendo por base seus valores digitais fornecidos.

Foram aplicadas conversão Radiométrica o qual é aplicado nas bandas e utilizado para executar transformações radiométricas nas imagens de satélite, em seguida foram feitas composições Coloridas RGB utilizando as bandas 5, 4 e 3; permitindo através do SIG a criação de uma única cena Multispectral com todas as bandas em sequência; por último foram feitas fusão de imagens com objetivo de utilizar a imagem multiespectral para colorir a Pancromática.

A classificação digital de imagem foi do tipo não supervisionado, tendo em vista a classificação exploratória de imagem. No final foi possível gerar 3 (três) classificações, citadas a seguir: floresta madura, vegetação secundária e áreas antropizadas. Após este procedimento, foi feita a edição da classificação, o arquivo foi transformado em arquivo de vetor (shapefile). Foram aleatorizados 150 pontos no mapa para verificar a acuracidade das informações apuradas, logo foi determinada matriz de erro e calculado o índice de Kappa, descrito a seguir.

$$
K=1-\frac{n m^{2}-\sum_{i=1}^{n} \sum_{j=1}^{k} x_{i j}^{2}}{n m(m-1) \sum_{j=1}^{k} p_{j}\left(1-p_{j}\right)}
$$

k: número de categorias totais; m: o número de ensaios para o caso $1, \mathrm{~m}=$ número de ensaios para cada avaliador; para o caso $2, \mathrm{~m}=$ número de ensaios para todos os avaliadores $\mathrm{n}$ : número de amostras;

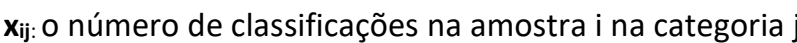

\section{RESULTADOS E DISCUSSÃO}

Analisando os dados de uso e ocupação do solo de Concórdia do Pará representado pela, verificouse que a classe de floresta madura 15222,69 ha $(7,3 \%)$, vegetação secundária 177713,8 ha $(85,8 \%)$ e áreas antropizadas com 14275,62 ha (6,9\%). De acordo com a figura 1 é possível identificar impacto visual, sobre o meio natural, logo a fragmentação da vegetação causa alteração e impermeabilização do solo, aumento da 
geração de resíduos sólidos e líquidos, tanto o meio biótico, interferência na fauna e flora alterando os habitats naturais, bem como o socioeconômico e com o aumento dos custos com saúde. Há o constante crescimento demográfico, e pode-se dizer que os problemas ambientais apresentados afetam diretamente desenvolvimento social e ambiental de todo o município, impactando na qualidade de vida dos habitantes.

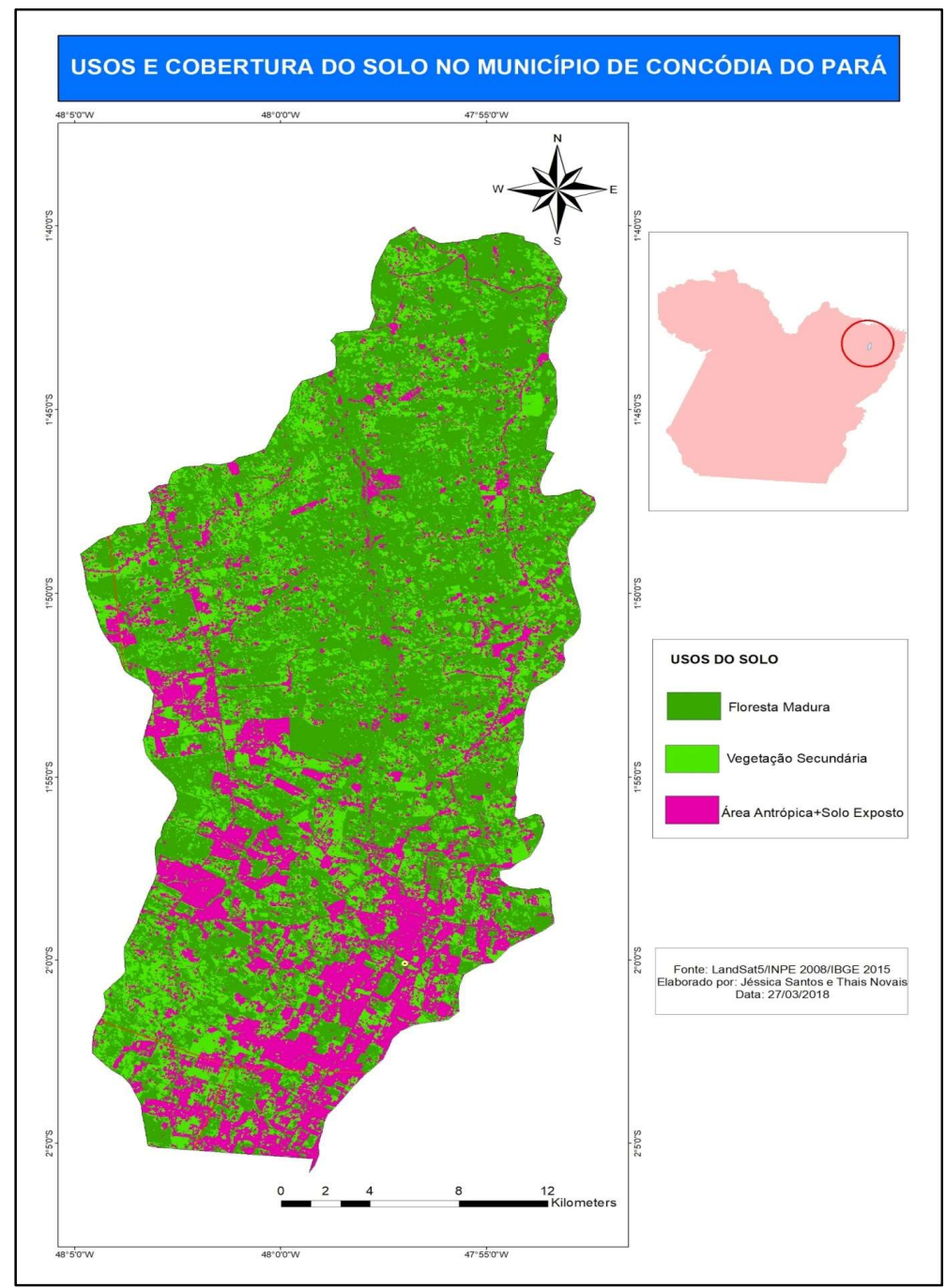

Figura 2: Mapa de uso e cobertura do solo no município de Concórdia do Pará.

Estima-se que município de Concórdia do Pará vivenciou desenvolvimento econômico em detrimento ao processo de urbanização dinâmico e instalações de agroindústrias, contudo, acredita-se que o aumento da população urbana trouxe consigo a necessidade de expansão do território urbano do município, com a construção de residências, aberturas de novas ruas. Ocasionando alterações da paisagem no município ocasionando a perda da cobertura vegetal.

Tabela 1: Matriz de erro da classificação não supervisionada de Concórdia do Pará.

\begin{tabular}{|l|l|l|l|l|}
\hline \multirow{2}{*}{ Dados classificados } & Dados de Referência & Total da Linha & \\
\cline { 2 - 5 } & Floresta Madura & Floresta Secundária & Áreas Antropizadas & \\
\hline Floresta Madura & 42 & 2 & 0 & 44 \\
\hline Floresta Secundária & 36 & 30 & 14 & 80 \\
\hline Áreas Antropizadas & 1 & 6 & 19 & 26 \\
\hline Total da coluna & 79 & 38 & 33 & 150 \\
\hline
\end{tabular}

Segundo Ferreira et al. (2007) a partir da construção da matriz de erro, como é descrita na tabela 1, 
é possível fazer a avaliação da verdade de campo usando critérios para comparação a exatidão de mapas, no entanto é preciso aplicar uma série de técnicas estatísticas descritivas e analíticas dos dados. Para conferir a exatidão é utilizado o índice de Kappa, a qual expressa à diferença entre a concordância dos dados de referência, classificação automática, e a probabilidade de concordância entre os dados (FERREIRA et al., 2007). Contudo, para um conhecimento mais profundo foi verificado a classificação da área; bem como a concordância entre o conjunto de dados o índice de Kappa chegou a 41,5 \% o que demonstra nível razoável de concordância.

\section{CONCLUSÕES}

Foi possível obter melhor compreensão espacial das atividades socioeconômicas e usos do solo, bem como a forma de ocupação no município de Concórdia do Pará, visto que neste município são desenvolvidas atividades de agricultura itinerante e forte influência de empresas privadas, embora não tenha sido possível se deslocar a campo para validação das áreas identificadas.

A partir da caracterização espacial da área foi possível alcançar ao objetivo proposto neste trabalho, utilizando técnicas de geoprocessamento para monitoramento que é importante para tomadas de decisões e planejamentos para melhor gerir os recursos naturais, no entanto alguns pontos limitantes da classificação que entre as classificações chegam a causar possibilidade de inconsistência do real, o que se faz de suma importância a validação de forma supervisionada para melhor avaliar o uso da terra.

\section{REFERÊNCIAS}

ARAÚJO FILHO, M. C.; MENESES, P. R.; SANO, E. E.. Sistema de classificação de uso e cobertura da Terra na análise de imagens de satélite. Revista Brasileira de Cartografia, v.59, n.2, 2007.

FERREIRA, E.; DANTAS, A. A. A.; MORAIS, A. R.. Exatidão na classificação de fragmentos de matas em imagem do satélite Cbers-CCD, no município de Lavras, MG. In: SIMPÓSIO BRASILEIRO DE SENSORIAMENTO REMOTO. Anais Florianópolis: INPE, 2007. p.887-894.

IBGE. Instituto Brasileiro de Geografia e Estatística. Panorama de Concórdia do Pará. Rio de Janeiro: IBGE, 2018.
LEITE, E. F.; ROSA, R.. Análise Do Uso, Ocupação E Cobertura Da Terra Na Bacia Hidrográfica Do Rio Formiga, Tocantins. Revista Eletrônica de Geografia, v.4, n.12, p.90-106, 2012.

LOPES, L. H. M.. Uso e cobertura do solo no município de Tailândia-PA utilizando o Tm/Landsat e técnica de classificação não-supervisionada. Rev. Bra. ENGEVISTA, v.10, n.2, p.126-132, 2008. DOI: https://doi.org/10.22409/engevista.v10i2.219

PINHEIRO, K. A. O.; OLIVEIRA, F. A. O.; RUSCHEL, A. R.; PITA, J. D.; SANTOS, G. C.; SILVA, F. L.; FRAZÃO, A. S.; CARNEIRO, F. S.; SOUZA, M. F. S.. Volumetric space distribution of wood as a tool in sustainable forest. African Journal of Agricultural Research, v.15, n.2, p.312-322, 2020. DOI: http://doi.org/10.5897/AJAR2018.13682

A CBPC - Companhia Brasileira de Produção Científica (CNPJ: 11.221.422/0001-03) detém os direitos materiais desta publicação. Os direitos referem-se à publicação do trabalho em qualquer parte do mundo, incluindo os direitos às renovações, expansões e disseminações da contribuição, bem como outros direitos subsidiários. Todos os trabalhos publicados eletronicamente poderão posteriormente ser publicados em coletâneas impressas sob coordenação da Sustenere Publishing, da Companhia Brasileira de Produção Científica e seus parceiros autorizados. Os (as) autores (as) preservam os direitos autorais, mas não têm permissão para a publicação da contribuição em outro meio, impresso ou digital, em português ou em tradução. 